\title{
Choline supply during negative nutrient balance alters hepatic cystathionine $\beta$-synthase, intermediates of the methionine cycle and transsulfuration pathway, and liver function in Holstein cows
}

\author{
D. N. Coleman, ${ }^{1}$ A. Alharthi, ${ }^{1}$ V. Lopreiato, ${ }^{2}$ E. Trevisi, ${ }^{3}$ M. Miura, ${ }^{4}$ Y.-X. Pan, ${ }^{5,6}$ and J. J. Loor ${ }^{1,6 *}$ \\ ${ }^{1}$ Department of Animal Sciences, University of Illinois, Urbana 61801 \\ ${ }^{2}$ Department of Health Science, Interdepartmental Services Centre of Veterinary for Human and Animal Health, \\ Magna Græcia University of Catanzaro, 88100 Catanzaro, Italy \\ ${ }^{3}$ Istituto di Zootecnica, Facoltà di Agraria, Università Cattolica del Sacro Cuore, 29122 Piacenza, Italy \\ ${ }^{4}$ Ajinomoto Co. Inc., 210-8681 Tokyo, Japan \\ ${ }^{5}$ Department of Food Science and Human Nutrition, University of Illinois, Urbana 61801 \\ ${ }^{6}$ Division of Nutritional Sciences, University of Illinois, Urbana 61801
}

\section{ABSTRACT}

Although choline requirements for cows are unknown, enhanced postruminal supply may decrease liver triacylglycerol and increase flux through the Met cycle to improve immunometabolic status during a negative nutrient balance (NNB). Our objectives were to investigate the effects of postruminal choline supply during a feed restriction-induced NNB on (1) hepatic activity cystathionine $\beta$-synthase and transcription of enzymes in the transsulfuration pathway and Met cycle; (2) hepatic metabolites in the Met cycle and the transsulfuration pathway, bile acids, and energy metabolism; and 3) plasma biomarkers of liver function, inflammation, and oxidative stress. Ten primiparous rumencannulated Holstein cows $(158 \pm 24 \mathrm{~d}$ postpartum) were used in a replicated $5 \times 5$ Latin square design with 4 -d treatment periods and $10 \mathrm{~d}$ of recovery (14 $\mathrm{d} /$ period). Treatments were unrestricted intake with abomasal infusion of water, restricted intake $(\mathrm{R} ; 60 \%$ of net energy for lactation requirements) with abomasal infusion of water, or R plus abomasal infusion of 6.25 , 12.5 , or $25 \mathrm{~g} / \mathrm{d}$ choline ion. Liver tissue was collected on d 5 after infusions ended, and blood was collected on d 1, 3, and 5. Statistical contrasts were A0 versus R0 (CONT1), $\mathrm{R}$ versus the average of choline doses (CONT2), and tests of linear and quadratic effects of choline dose. Activity of cystathionine $\beta$-synthase was lower with R (CONT1) and decreased linearly with choline. Hepatic glutathione was not different with $\mathrm{R}$ or choline, but taurine tended to be greater with choline (CONT2). Betaine and carnitine were greater with R (CONT1) and further increased with choline

Received January 30, 2019.

Accepted March 18, 2019.

*Corresponding author: jloor@illinois.edu
(CONT2). Concentrations of $\mathrm{NAD}^{+}$were greater with choline (CONT2). Cholic and glycol-chenodeoxycholic acids were decreased by $\mathrm{R}$ and choline, while taurocholic and tauro-chenodeoxycholic acids were not altered. Plasma aspartate aminotransferase and bilirubin were greater with R (CONT1) but decreased with choline (CONT2). Paraoxonase was lower with $\mathrm{R}$ and increased with choline (CONT2). Data suggest that enhanced supply of choline during NNB decreases entry of homocysteine to the transsulfuration pathway, potentially favoring remethylation to Met by acquiring a methyl group from betaine. As such, Met may provide methyl groups for synthesis of carnitine. Along with production data indicating that $12.5 \mathrm{~g} / \mathrm{d}$ choline ion improved milk yield and liver fatty acid metabolism during NNB, the changes in blood biomarkers also suggest a beneficial effect of choline supply on liver function and oxidative stress.

Key words: 1-carbon metabolism, lactation, methyl donors, oxidative stress

\section{INTRODUCTION}

During the periparturient period, dairy cows enter a period of negative nutrient balance (NNB) in which lipid mobilization increases, resulting in greater nonesterified fatty acid (NEFA) uptake by the liver and increased triacylglycerol (TAG) accumulation (Loor et al., 2013; Du et al., 2018). This period of NNB is also associated with increased disease incidence and suboptimal production (Roche et al., 2013). While many studies have investigated the potential for choline to alleviate hepatic TAG accumulation in periparturient cows (Cooke et al., 2007; Zom et al., 2011; Elek et al., 2013), choline may also have immunomodulatory effects via Met (Vailati-Riboni et al., 2017) and may be beneficial in alleviating the inflammatory response that 
often accompanies lipid accumulation in the liver (Li et al., 2015; Zhu et al., 2018).

Choline can be oxidized to betaine, which is used as a methyl donor in the synthesis of Met from homocysteine (remethylation) via betaine homocysteine methyltransferase (BHMT; Figure 1) (Li and Vance, 2008). Methionine can also be synthesized from homocysteine via 5-methyltetrahydrofolate-homocysteine methyltransferase (MTR). Therefore, enhanced supply of choline may increase flux through the Met cycle, enhancing availability of $S$-adenosylmethionine (SAM; Vance et al., 1997) to support phosphatidylcholine and carnitine production (Pinotti et al., 2002). Increasing production of phosphatidylcholine (Fast and Vance, 1995) and carnitine (Grum et al., 1996) may help the liver metabolize the excess NEFA during NNB.

Homocysteine is also used to synthesize cystathionine via cystathionine $\beta$-synthase (CBS) in the first reaction of the transsulfuration pathway (Banerjee et al., 2003). Cystathionine is used to make cysteine, which is in turn used to synthesize the antioxidants taurine and glutathione (GSH). Cystathionine $\beta$-synthase is allosterically activated by SAM (Banerjee et al., 2003). Thus, enhanced choline supply may indirectly increase flux through the transsulfuration pathway, enhancing production of taurine and GSH via increased SAM. Increasing antioxidant production may alleviate oxidative stress and inflammation in the liver due to increased reactive oxygen metabolite (ROM) production (Osorio et al., 2014b; Zhou et al., 2016b; Batistel et al., 2018). Choline has been shown to alleviate oxidative stress in nonruminants (Sachan et al., 2005; Mehta et al., 2009; Wu et al., 2014). However, effects in dairy cattle are not entirely clear. One study with rumen-protected choline (RPC) reported no changes in markers of oxidative stress (Zhou et al., 2016a), whereas another reported enhanced antioxidant capacity (Sun et al., 2016).

The choline requirement for dairy cattle is unknown (NRC, 2001). Previous studies with RPC have suggested that the optimal amount needed for periparturient cows is $12.5 \mathrm{~g} / \mathrm{d}$ (Zom et al., 2011; Zhou et al., 2016c). Recent work by de Veth et al. (2016) with lactating cows in positive nutrient balance reported that abomasal infusions of choline chloride for $5 \mathrm{~d}$ at 12.5 and $25 \mathrm{~g} / \mathrm{d}$ increased the appearance of choline and its metabolites betaine and phosphocholine in the portal vein. In the context of physiologic adaptations during an NNB, a clear benefit would follow from determining not only optimal amounts of postruminally delivered choline, but also mechanisms in methyl donor

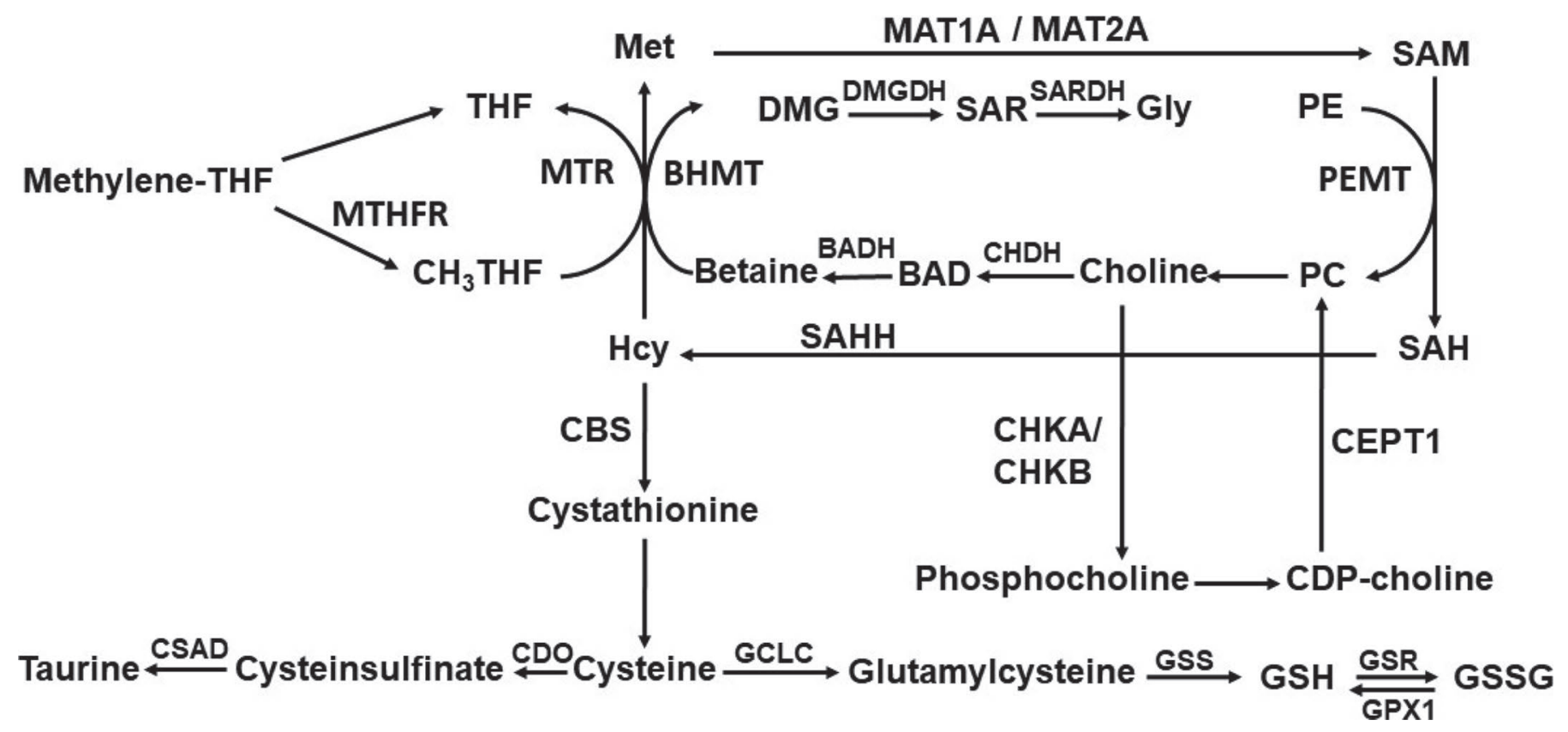

\footnotetext{
Figure 1. Methionine and choline metabolism. BADH = betaine aldehyde dehydrogenase; CBS = cystathionine $\beta$-synthase; CDO $=$ cysteine dioxygenase; CEPT1 = choline/ethanolamine phosphotransferase $1 ; \mathrm{CHDH}=$ choline dehydrogenase; $\mathrm{CHK}=$ choline kinase; $\mathrm{CSAD}=$ cysteine sulfinic acid decarboxylase; DMG = dimethylglycine; DMGDH = dimethylglycine dehydrogenase; GCLC = glutamate-cysteine ligase catalytic subunit; GPX1 = glutathione peroxidase 1; GSH = reduced glutathione; GSR = glutathione reductase; GSS = glutathione synthase; GSSG $=$ glutathione disulfide; Hcy = homocysteine; MAT = methionine adenosyltransferase; MTHFR = methylenetetrahydrofolate reductase; MTR $=$ 5-methyltetrahyrdofolate-homocysteine methyltransferase; $\mathrm{PC}=$ phosphatidylcholine; $\mathrm{PCYT}=$ phosphate cytidylyltransferase; $\mathrm{PE}=$ phosphatidylethanolamine; PEMT = phosphatidylethanolamine methyltransferase; $\mathrm{SAH}=S$-adenosylhomocysteine; $\mathrm{SAHH}=S$-adenosylhomocysteine hydrolase; SAM $=S$-adenosylmethionine; $\mathrm{SAR}=$ sarcosine; $\mathrm{SARDH}=$ sarcosine dehydrogenase; $\mathrm{THF}=$ tetrahydrofolate; $\mathrm{BHMT}=$ betaine homocysteine methyltransferase; $\mathrm{CDP}=$ cytidine diphosphate.
} 
metabolism responsive to choline that may improve liver function.

Our general hypothesis was that incremental postruminal supply of choline during a feed restriction-induced NNB would improve liver function and alleviate inflammation and oxidative stress. Our objectives were to investigate the effects of postruminal choline supply during a feed restriction-induced NNB on (1) hepatic activity of CBS and transcription of enzymes in the transsulfuration pathway and Met cycle; (2) hepatic concentration of metabolites in the Met cycle and transsulfuration pathway, bile acid synthesis, and energy metabolism; and (3) concentration of plasma biomarkers of liver function, inflammation, and oxidative stress.

\section{MATERIALS AND METHODS}

\section{Experimental Design and Treatments}

All procedures involving animals received approval from the Institutional Animal Care and Use Committee at the University of Illinois (protocol no. 16176). Ten primiparous rumen-cannulated Holstein cows (158 \pm 24 postpartum) were used in a $5 \times 5$ replicated Latin square design. Periods were $14 \mathrm{~d}$ in length, with 4-d treatment periods (d 1-4) and $10 \mathrm{~d}$ of recovery (d 5-14). Treatment periods of $4 \mathrm{~d}$ were chosen based on preliminary observations that suggested concentrations of NEFA and BHB stabilized and began to return to normal after $4 \mathrm{~d}$ of feed restriction at $60 \%$ of $\mathrm{NE}_{\mathrm{L}}$ requirements (unpublished data). The 10-d recovery periods were also chosen based on preliminary observations that suggested that milk yields and concentrations of NEFA and BHB had returned to baseline levels $10 \mathrm{~d}$ after feed restriction at $60 \%$ of $\mathrm{NE}_{\mathrm{L}}$ requirements (unpublished data). Treatments in the present study were ad libitum intake with abomasal infusion of water (A0), restricted intake $(\mathbf{R} ; 60 \%$ of net energy for lactation requirements) with abomasal infusion of water (R0) or R plus abomasal infusion of 6.25 (R6.25), 12.5 (R12.5), or $25(\mathbf{R 2 5}) \mathrm{g} / \mathrm{d}$ choline ion. The diet was provided as TMR and formulated to meet NRC (2001) requirements (Table 1). Diets were fed once daily at $0800 \mathrm{~h}$. The restricted intakes were calculated based on NRC equations to provide $60 \%$ of the $\mathrm{NE}_{\mathrm{L}}$ at the start of each treatment period as described previously (Moyes et al., 2009). All cows returned to ad libitum intake during the 10-d recovery period.

The choline was provided as aqueous choline chloride $(70 \%$, Balchem Corp., New Hampton, NY). The doses of $6.25,12.5$, and $25 \mathrm{~g} / \mathrm{d}$ represent the amount of choline ion that was supplied postruminally, and they were achieved by providing $12.0,23.9$, and $47.9 \mathrm{~g} / \mathrm{d}$ of choline chloride. Doses above and below the suggested requirement of $12.5 \mathrm{~g} / \mathrm{d}$ of choline allowed for the determination of linear and quadratic responses of postruminal choline ion supplementation. Abomasal infusions were accomplished by passing an infusion line through the rumino-omasal orifice into the abomasum by way of the rumen cannula. An infusion line (Tygon tubing), fitted with a $60-\mathrm{mL}$ plastic bottle with the bottom removed and with an approximately 8 -cm rubber flange, was inserted into the abomasum. The tubing was in place for the duration of the study and was checked daily for proper placement. The infusion apparatus was connected to an external infusion line via a hole in the rumen cannula plug. The internal and external lines were connected by way of quick-disconnect fitting to allow disconnection for milking. The treatment solutions were provided by mixing the $70 \%$ choline chloride with deionized tap water and were infused continuously using rotary peristaltic pumps with their corresponding 1,200-mL bag (Sentinel Enteral Feeding Pump, Alcor Scientific Inc., Smithfield, RI). A daily volume of 3,600 $\mathrm{mL} /$ cow (three 1,200-mL bags per day) was infused during the 4 -d treatment period. Infusions were initiated after cows returned from the $0400 \mathrm{~h}$ milking on $\mathrm{d}$ 1 , and ran continuously until they were ended on the morning of $\mathrm{d} 5$ at the $0400 \mathrm{~h}$ milking. Because the cows were milked 3 times a day $(0400,1200$, and $1930 \mathrm{~h})$, a new infusion bag was hooked up after each milking.

Table 1. Ingredient composition (\% of DM) of the diet

\begin{tabular}{lc}
\hline Item & Content \\
\hline Ingredient & \\
Alfalfa hay & 9.26 \\
Ajipro-L-G3 & 0.11 \\
Canola meal & 15.15 \\
Corn gluten meal & 4.56 \\
Corn silage & 41.33 \\
Ground shelled corn & 23.24 \\
ProVAAL2 AADvantage & 0.96 \\
Smartamine M ${ }^{3}$ & 0.07 \\
Soy hulls & 1.69 \\
Vitamin-mineral mix ${ }^{4}$ & 3.57 \\
Zinpro Availa-Dairy & 0.06 \\
Chemical analysis & 16.00 \\
CP & 20.00 \\
ADF & 18.19 \\
NDF & 3.05 \\
Ether extract & 1.71 \\
NE ${ }_{\mathrm{L}}$, Mcal/kg & \\
${ }^{1}$ Ajinomoto Heartland Inc., Chicago, IL. & \\
${ }^{2}$ Perdue AgriBusiness, Salisbury, MD. & \\
${ }^{3}$ Adisseo, Alpharetta, GA. & \\
${ }^{4}$ Contained a minimum of 12.5\% Ca, 10.4\% Na, 2.2\% Mg, $8.0 \% \mathrm{~K}$, \\
0.1\% S, 7.1\% Se, 244.5 kIU of vitamin A/kg, 48.9 kIU of vitamin $\mathrm{D}_{3} /$ \\
kg, and 0.922 kIU of vitamin E/kg. \\
${ }^{5}$ Zinpro Corporation, Eden Prairie, MN.
\end{tabular}




\section{Blood Collection and Analyses}

Blood was sampled from the coccygeal vein after the morning milking, approximately $3 \mathrm{~h}$ before feeding, on d 1, 3, and 5. Samples were collected into vacutainer tubes containing lithium heparin (BD Vacutainer, Becton, Dickinson and Co., Franklin Lakes, NJ) and placed on ice. Plasma was obtained by centrifugation at 2,000 $\times g$ for $15 \mathrm{~min}$ at $4^{\circ} \mathrm{C}$, and aliquots were stored at $-80^{\circ} \mathrm{C}$ until further analysis. Glucose, albumin, total cholesterol, total bilirubin, creatinine, urea, aspartate aminotransferase (AST), $\gamma$-glutamyl transpeptidase (GGT), alkaline phosphatase, total plasma ROM, ferric reducing ability of plasma (FRAP), haptoglobin, ceruloplasmin, nitric oxide and nitric oxide metabolites, paraoxonase $(\mathbf{P O N})$ activity, vitamin $\mathrm{A}$, vitamin $\mathrm{E}$, and $\beta$-carotene were analyzed as described by Trevisi et al. (2013). Myeloperoxidase was measured as described by Bionaz et al. (2007).

\section{Liver Biopsy and Tissue Analysis}

Liver biopsies were conducted on the morning of $\mathrm{d} 5$ when cows returned from the $0400 \mathrm{~h}$ milking (within 1 $\mathrm{h}$ of the infusions ending) using a similar technique described by Vailati Riboni et al. (2015). An 18-gauge by 10.2-cm bone marrow probe (Monoject-8881-247087; Medtronic, Minneapolis, MN) was used to obtain approximately $2 \mathrm{~g}$ (wet weight) of liver. Samples were snap frozen in liquid nitrogen and subsequently stored at $-80^{\circ} \mathrm{C}$.

Approximately $150 \mathrm{mg}$ of frozen tissue was extracted for metabolomics analysis using the 2-step protocol described by $\mathrm{Wu}$ et al. (2008). Targeted metabolomics (LC/MS/MS) was performed to quantify metabolites related to 1-carbon metabolism, the transsulfuration pathway, the tricarboxylic acid (TCA) cycle, and bile acid synthesis. Samples were analyzed with the 5500 QTRAP LC/MS/MS system (Sciex, Framingham, MA) in the Metabolomics Laboratory of the Roy J. Carver Biotechnology Center, University of Illinois at Urbana-Champaign. Details of the system and analysis are provided in Supplemental File and Table S1 (https: //doi.org/10.3168/jds.2019-16406). Total RNA was extracted from liver tissue and quantitative PCR performed as described previously (Osorio et al., 2014a). Quantitative PCR performance and primer information are included in Supplemental Tables S2 and S3 (https: //doi.org/10.3168/jds.2019-16406). Activity of CBS was measured as described by Zhou et al. (2017). Total and oxidized GSH in liver tissue were measured using a commercial kit (cat. no. NWH-GSH01; Northwest Life Science Specialties LLC, Vancouver, WA). Reduced
GSH was calculated as reduced GSH = total GSH oxidized GSH.

\section{Statistical Analyses}

Data were analyzed as a replicated $5 \times 5$ Latin square using the MIXED procedure of SAS 9.4 (SAS Institute Inc., Cary, NC). The model tested the random effects of square and cow within square and the fixed effects of period and treatment. Covariance structures compared were compound symmetry, autoregressive order 1, autoregressive heterogeneous order 1 , unstructured, and Toeplitz. The compound symmetry structure was used based on the corrected Akaike information criterion. The Kenward-Roger degrees of freedom approximation was used to determine the denominator degrees of freedom for tests of fixed effects. The CONTRAST statement of SAS was used to perform orthogonal contrasts: CONT1 $=\mathrm{A} 0$ compared with R0; CONT2 = R0 compared with the average of the 3 choline treatments; and the linear and quadratic effects of R0, R6.25, R12.5, and R25. Contrasts were adjusted using the IML procedure to reflect uneven spacing of treatments.

The mRNA abundance data were $\log _{2}$-scale transformed to fit normal distribution of residuals. Tables and graphs contain the $\log _{2}$ back-transformed means that resulted from the statistical analysis. Least squares means and standard errors were determined using the LSMEANS statement of SAS.

\section{RESULTS}

\section{Met and Choline Metabolism Pathway}

The hepatic mRNA abundance for genes in the Met and choline metabolism pathways are presented in Table 2. Abundance of choline dehydrogenase $(\mathrm{CHDH})$ was lower with $\mathrm{R}(P=0.07$; CONT1) and choline supply $(P=0.08 ;$ CONT2). The abundance of dimethylglycine dehydrogenase $(D M G D H)$ was greater with choline supply $(P=0.02$; CONT2). Sarcosine dehydrogenase was lower with $\mathrm{R}(P<0.001 ; \mathrm{CONT} 1)$. Abundance of betaine aldehyde dehydrogenase did not differ with $\mathrm{R}$ or choline supply $(P>0.10)$.

\section{Transsulfuration Pathway}

The activity of CBS and the mRNA abundance results for genes in the transsulfuration pathway are reported in Table 2. Activity of CBS was lower with $\mathrm{R}(P$ $=0.07$; CONT1) and decreased linearly with increasing choline dose $(P=0.03)$. However, abundance of $C B S$ was not different with $\mathrm{R}$ or choline supply $(P>0.10)$. 
The abundance of cysteine dioxygenase 1 (CDO1) and cysteine sulfinic acid decarboxylase $(C S A D)$ was reduced with $\mathrm{R}(P=0.02$ and $P<0.001$, respectively; CONT1). A tendency for a quadratic effect was also observed for $C D O 1(P=0.07)$, with R12.5 having the greatest abundance. Choline supply reduced the mRNA abundance of glutamate-cysteine ligase $(G C L)$ catalytic subunit $(G C L C)$ compared with $\mathrm{R} 0(P=$ 0.07; CONT2). A quadratic effect was also observed for $G C L C(P=0.04)$; the abundance decreased from R0 to R6.25, but then increased from R12.5 to R25. Restriction (CONT1) reduced the abundance of glutathione synthase $(G S S ; P<0.001)$ and glutathione reductase (GSR; $P<0.001)$. Additionally, a quadratic tendency existed, with the abundance of $G S S$ decreasing from R0 through R12.5 and then increasing with R25 ( $P=$ $0.10)$. Last, glutathione peroxidase 1 (GPX1) mRNA abundance was lower with choline supply compared with R0 $(P=0.01$; CONT2), and a quadratic effect $(P$ $=0.06)$ of choline dose was observed.

\section{Liver Metabolites}

Methionine and Choline Metabolism. The effects of $\mathrm{R}$ and choline on hepatic metabolites involved in Met and choline metabolism are presented in Table 3 . Liver betaine was greater with $\mathrm{R}(P=0.02$; CONT1 $)$ and increased further with choline supply $(P<0.001$; CONT2). This increase was linear across choline dose $(P<0.001)$. Choline concentrations in liver tissue increased linearly across choline dose $(P=0.001)$. The concentration of Gly was greater with $\mathrm{R}(P=0.04$; CONT1). Liver acetylcholine/butyrobetaine, which could not be detected separately, increased linearly across choline dose $(P=0.03)$.

Transsulfuration Pathways. The concentrations of metabolites in the transsulfuration pathway are presented in Table 3. No differences were detected in the concentrations of total GSH or reduced GSH with R or choline $(P>0.10)$. Restriction (CONT1) reduced the concentrations of cystathionine $(P=0.001)$, hypotaurine $(P<0.001)$, and Ser $(P=0.001)$. Concentrations of Ser also tended to decrease with choline compared with R0 $(P=0.10$; CONT2). Last, taurine concentrations in the liver tended to increase with choline $(P=$ 0.09; CONT2).

Energy Metabolism. The results for metabolites involved in energy metabolism and the TCA cycle are presented in Table 3. Of the 23 metabolites measured in these pathways, only 7 were detected. The concen-

Table 2. Least squares means and pooled SEM for hepatic activity of cystathionine $\beta$-synthase (CBS) and mRNA abundance of genes in the methionine cycle and transsulfuration pathways in Holstein cows fed 5 different treatments ${ }^{1}$ over a period of $4 \mathrm{~d}$

\begin{tabular}{|c|c|c|c|c|c|c|c|c|c|c|}
\hline Item $^{2}$ & \multicolumn{5}{|c|}{ Treatment } & \multicolumn{5}{|c|}{$P$-value ${ }^{3}$} \\
\hline \multicolumn{11}{|c|}{$\begin{array}{l}\text { Enzyme activity, nmol of product. } \\
\mathrm{h}^{-1} \cdot \mathrm{mg} \text { of protein }\end{array}$} \\
\hline CBS & 36.99 & 29.44 & 29.81 & 26.29 & 22.15 & 3.07 & 0.07 & 0.29 & 0.03 & 0.70 \\
\hline$B A D H$ & 1.17 & 1.17 & 1.20 & 1.19 & 1.17 & 0.06 & 0.99 & 0.69 & 0.80 & 0.47 \\
\hline $\mathrm{CHDH}$ & 1.37 & 1.06 & 0.87 & 0.86 & 0.91 & 0.17 & 0.07 & 0.08 & 0.39 & 0.14 \\
\hline$D M G D H$ & 0.89 & 1.00 & 1.18 & 1.13 & 1.10 & 0.10 & 0.13 & 0.02 & 0.42 & 0.06 \\
\hline$S A R D H$ & 1.29 & 0.87 & 0.91 & 0.95 & 0.92 & 0.05 & $<0.001$ & 0.12 & 0.29 & 0.17 \\
\hline \multicolumn{11}{|c|}{$\begin{array}{l}\text { Transsulfuration pathway, } \log _{2} \\
\text { back transformed }\end{array}$} \\
\hline$C B S$ & 1.07 & 1.05 & 1.06 & 1.07 & 1.05 & 0.06 & 0.75 & 0.82 & 0.95 & 0.67 \\
\hline$G S S$ & 1.36 & 0.95 & 0.91 & 0.89 & 0.93 & 0.05 & $<0.001$ & 0.21 & 0.73 & 0.10 \\
\hline
\end{tabular}

${ }^{1} \mathrm{~A} 0=$ ad libitum intake, abomasal infusion of water; $\mathrm{R} 0=$ restricted intake, abomasal infusion of water; R6.25 = restricted intake, abomasal infusion of $6.25 \mathrm{~g} / \mathrm{d}$ of choline; R12.5 = restricted intake, abomasal infusion of $12.5 \mathrm{~g} / \mathrm{d}$ of choline; R25 = restricted intake, abomasal infusion of 25 $\mathrm{g} / \mathrm{d}$ of choline. Choline was provided via $70 \%$ aqueous solution of choline chloride (Balchem Corporation, New Hampton, NY) mixed with water. ${ }^{2} B A D H=$ betaine aldehyde dehydrogenase; $C B S=$ cystathionine $\beta$-synthase; $C H D H=$ choline dehydrogenase; $C D O 1=$ cysteine dioxygenase; $C S A D=$ cysteine sulfinic acid decarboxylase; $D M G D H=$ dimethylglycine dehydrogenase; $G C L C=$ glutamate-cysteine ligase, catalytic subunit; $G P X 1=$ glutathione peroxidase $1 ; G S R=$ glutathione reductase; $G S S=$ glutathione synthase; $S A R D H=$ sarcosine dehydrogenase.

${ }^{3}$ Contrasts: $1=\mathrm{A} 0$ compared with R0; $2=\mathrm{R} 0$ compared with the average of the 3 treatments $(6.25,12.5$, and $25 \mathrm{~g} / \mathrm{d}$ of choline). Linear (L) and quadratic (Q) effects of treatments R0, R6.25, R12.5, and R25. 


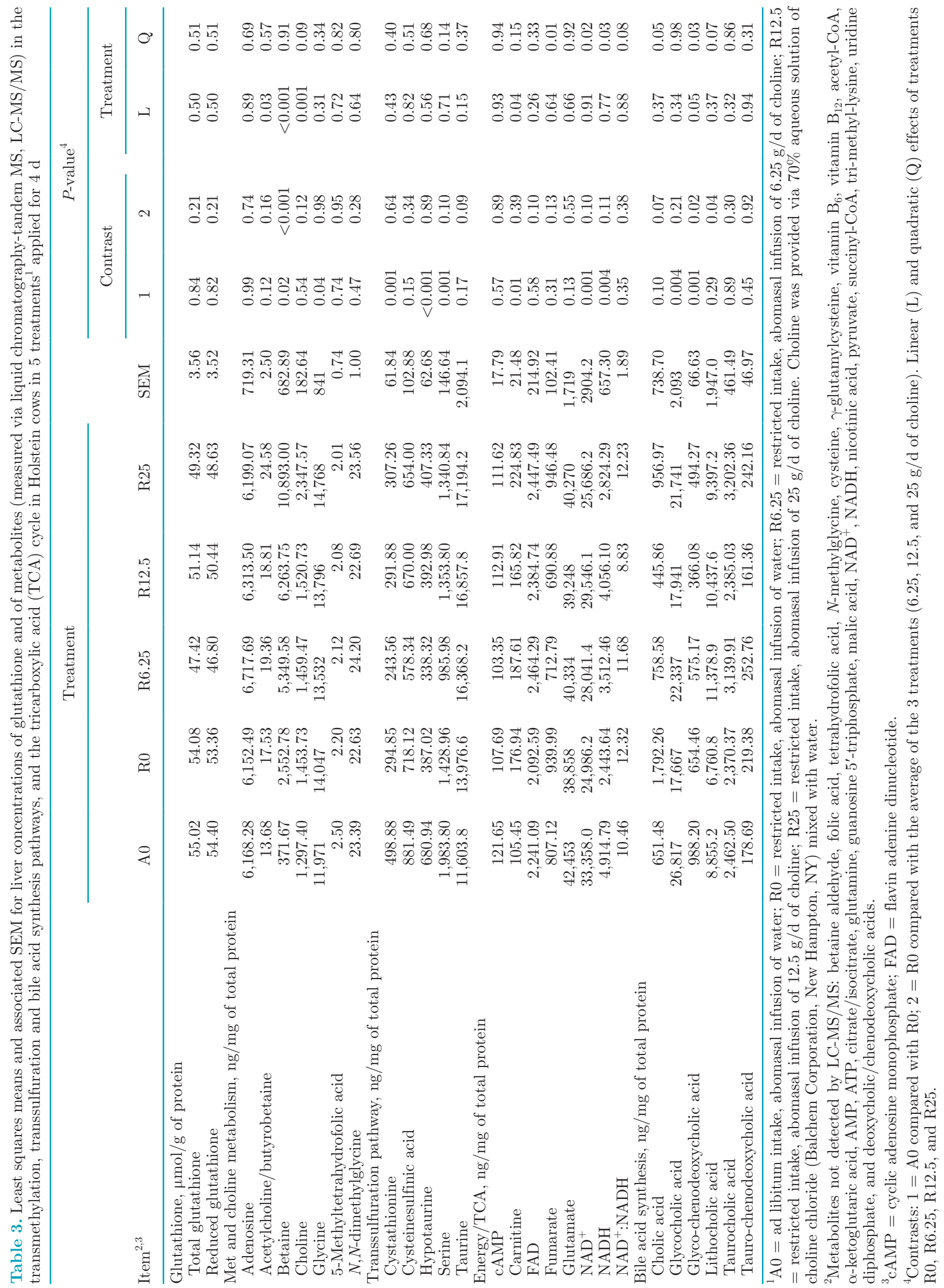


tration of carnitine was greater with $\mathrm{R}(P=0.01$; CONT1) and increased linearly with choline $(P=0.04)$; however, R6.25 had the lowest concentration. Choline supply tended to increase the concentration of flavin adenine dinucleotide (FAD; $P=0.10$; CONT2) relative to R0. A quadratic effect $(P=0.01)$ was observed for hepatic fumarate concentration, with concentration decreasing from R0 through R12.5, but then increasing with R25. Restriction (CONT1) led to lower concentrations of $\mathrm{NAD}^{+}(P=0.001 ; \mathrm{CONT} 1)$ and NADH $(P=$ $0.004)$. Choline supply also tended to increase the concentration of $\mathrm{NAD}^{+}$relative to $\mathrm{R} 0(P=0.10$; CONT2). However, a quadratic increase occurred in both $\mathrm{NAD}^{+}$ $(P=0.02)$ and NADH $(P=0.03)$ across choline dose, with R12.5 having the greatest concentration. A quadratic effect was also observed for the ratio of $\mathrm{NAD}^{+}$to NADH $(P=0.08)$, with R12.5 having the lowest ratio.

Bile Acid Synthesis. The data for concentrations of hepatic metabolites in bile acid synthesis are presented in Table 3. Restriction (CONT1) led to lower concentrations of glycocholic acid $(P=0.004)$ and glyco-chenodeoxycholic acid $(P=0.001)$. Glycochenodeoxycholic acid decreased with choline supply $(P$ $<0.001$; CONT2) and the decrease was quadratic $(P$ $=0.03)$, with R12.5 having the lowest concentration. Cholic acid tended to be greater with $\mathrm{R}(P=0.10$; CONT1) but tended to be lower with choline compared with R0 $(P=0.07$; CONT2). The decrease in cholic acid with choline was quadratic $(P=0.05)$, with the R12.5 having the least hepatic cholic acid. Last, lithocholic acid increased with choline relative to R0 $(P=$ $0.04 ;$ CONT2). A quadratic effect was also observed for lithocholic acid $(P=0.07)$, with concentrations increasing from $\mathrm{R} 0$ to $\mathrm{R} 6.25$, but then decreasing with R12.5 and R25.

\section{Plasma Biomarkers}

Energy Metabolism. Plasma biomarker results related to energy metabolism are presented in Table 4. Concentrations of creatinine in plasma were greater with $\mathrm{R}(P=0.07$; CONT1), while plasma glucose was lower with $\mathrm{R}(P<0.001$; CONT1 $)$ and was further reduced with choline supply $(P<0.001$; CONT2). A treatment $\times$ day interaction was also observed (Supplemental Figure S1; https://doi.org/10.3168/jds.2019 -16406) for plasma glucose $(P=0.002)$ and urea $(P=$ $0.01)$.

Liver Function. Results for the plasma biomarkers related to liver function are presented in Table 4. Alkaline phosphatase in plasma was lower with $\mathrm{R}(P=$ 0.05 ; CONT1) and increased linearly with increasing choline $(P=0.02)$, except for R12.5, which had the lowest plasma alkaline phosphatase. The level of AST was greater with $\mathrm{R}(P=0.01$; CONT1 $)$ but decreased with choline relative to $\mathrm{R} 0(P=0.001$; CONT2 $)$. The decrease in AST with choline was quadratic $(P$ $=0.001$ ), with R12.5 being associated with the lowest level. Concentrations of cholesterol tended to be greater in plasma with $\mathrm{R}(P=0.09$; CONT1), whereas $\gamma$-glutamyl transferase in plasma was greater with $\mathrm{R}(P$ $=0.01$; CONT1). Plasma PON was lower with $\mathrm{R}(P=$ 0.02 ; CONT1) but increased with choline supply compared with R0 $(P=0.04$; CONT2). Total bilirubin in plasma was greater with $\mathrm{R}(P<0.001$; CONT1), while choline decreased total bilirubin compared with R0 $(P$ $=0.01 ;$ CONT2). However, the concentration of total bilirubin changed quadratically in response to choline supply $(P=0.06)$, with a decrease from R0 to R6.25 and then increases with R12.5 and R25. Treatment $\times$ day interactions (Supplemental Figure S2; https://doi .org/10.3168/jds.2019-16406) were observed for plasma alkaline phosphatase $(P<0.001)$ AST $(P=0.003)$, GGT $(P=0.02)$, and total bilirubin $(P=0.06)$.

Inflammation and Oxidative Stress. Results for plasma biomarkers of inflammation and oxidative stress are reported in Table 4 . No differences $(P>0.10)$ were observed for the markers of inflammation: albumin, ceruloplasmin, haptoglobin, and myeloperoxidase. The biomarker of antioxidant capacity ferric reducing ability was lower with $\mathrm{R}(P=0.01$; CONT1). Plasma nitrogen oxide was lower with $\mathrm{R}(P=0.04$; CONT1). The concentration of nitrite $\left(\mathrm{NO}_{2}^{-}\right)$decreased linearly with choline $(P=0.06)$. In contrast, nitrate $\left(\mathrm{NO}_{3}{ }^{-}\right)$ concentration was greater with $\mathrm{R}(P=0.06 ; \mathrm{CONT} 1)$ but tended to decrease with choline $(P=0.06$; CONT2). The decrease in nitrate with choline was quadratic across choline dose $(P=0.04)$; concentrations decreased from R0 to R6.25, but then increased with R12.5 and R25. Plasma $\alpha$-tocopherol decreased linearly with choline $(P=0.08)$, while $\beta$-carotene decreased quadratically $(P=0.08)$. However, R12.5 led to the greatest concentrations of both. Additionally, plasma concentrations of retinol decreased with $\mathrm{R}(P=0.03$; CONT1). A treatment $\times$ day interaction (Supplemental Figure S3; https://doi.org/10.3168/jds.2019-16406) was observed for retinol $(P=0.03)$, nitrogen oxide $(P$ $=0.08)$, and $\operatorname{FRAP}(P=0.06)$.

\section{DISCUSSION}

\section{Markers of Energy Metabolism}

Data on BW, energy balance, milk yield, and plasma concentrations of NEFA, BHB, and glucose clearly confirmed that our feed restriction model successfully 
induced an NNB (Coleman et al., 2019). Carnitine is essential for the transport of long-chain fatty acyl-CoA into the mitochondria via carnitine palmitoyltransferase-1 (CPT1; Rebouche and Seim, 1998). As such, the observed increase in carnitine with $\mathrm{R}$ may have helped support increased fatty acid oxidation due to the increase in NEFA mobilization. The change in carnitine with choline (especially R12.5) fits our hypothesis that the decrease in liver TAG content and the upregulation of CPT1A with choline were associated with increased fatty acid oxidation (Coleman et al., 2019). Although the major source of carnitine within the liver is via uptake as a result of transport from skeletal muscle (Bremer, 1983), hepatic carnitine could also be synthesized endogenously from butyrobetaine via $\gamma$-butyrobetaine hydroxylase or from metabolism of the amino acids Met and Lys; Met serves as a methyl donor to synthesize trimethyllysine using SAM (Carter et al., 1995). Greater remethylation of homocysteine (discussed below) may have supported synthesis of carnitine, resulting in the linear increase detected here. Although we did not measure enzymes involved in the synthesis of carnitine, the fact that trimethyllysine could not be detected in the present study may suggest a fast metabolism and partly support our hypothesis. In addition, while we could not detect butyrobetaine separately from acetylcholine, the linear increase in their concentration with increasing doses of choline may also have contributed to an increase in carnitine synthesis.

Nicotinamide adenine dinucleotide is a redox carrier that is involved in many oxido-reductive pathways such as amino acid catabolism, $\beta$-oxidation, the TCA cycle, electron transport chain, and the urea cycle (Strømland et al., 2019). The decreases in $\mathrm{NAD}^{+}$and $\mathrm{NADH}$ that we observed with $\mathrm{R}$ are likely due to the reduction in energy status with NNB. Although the ratio of $\mathrm{NAD}^{+} /$ $\mathrm{NADH}$ was not altered, the greater $\mathrm{NAD}^{+}$and $\mathrm{NADH}$

Table 4. Least squares means and associated pooled SEM for plasma concentrations of biomarkers of energy metabolism, liver function, inflammation, and oxidative stress in Holstein cows fed 5 different treatments ${ }^{1}$ over a period of $4 \mathrm{~d}$

\begin{tabular}{|c|c|c|c|c|c|c|c|c|c|c|}
\hline \multirow[b]{2}{*}{ Item $^{2}$} & \multicolumn{5}{|c|}{ Treatment } & \multirow[b]{2}{*}{ SEM } & \multicolumn{4}{|c|}{ Contrast $^{3}$} \\
\hline & A0 & R0 & $\mathrm{R} 6.25$ & $\mathrm{R} 12.5$ & $\mathrm{R} 25$ & & 1 & 2 & $\mathrm{~L}$ & $\mathrm{Q}$ \\
\hline \multicolumn{11}{|l|}{ Energy metabolism } \\
\hline Creatinine, $\mu \mathrm{mol} / \mathrm{L}$ & 87.64 & 89.17 & 90.83 & 89.36 & 89.57 & 1.42 & 0.07 & 0.26 & 0.86 & 0.39 \\
\hline Glucose ${ }^{4} \mathrm{mmol} / \mathrm{L}$ & 4.71 & 4.43 & 4.39 & 4.40 & 4.44 & 0.06 & $<0.001$ & 0.67 & 0.80 & 0.85 \\
\hline Urea,${ }^{4} \mathrm{mmol} / \mathrm{L}$ & 4.64 & 4.95 & 4.90 & 4.85 & 4.72 & 0.18 & 0.12 & 0.43 & 0.23 & 0.95 \\
\hline \multicolumn{11}{|l|}{ Liver function } \\
\hline Cholesterol, $\mathrm{mmol} / \mathrm{L}$ & 5.74 & 6.61 & 5.87 & 6.20 & 5.96 & 0.32 & 0.09 & 0.64 & 0.84 & 0.71 \\
\hline $\mathrm{GGT},{ }^{4} \mathrm{U} / \mathrm{L}$ & 42.42 & 47.82 & 47.36 & 47.73 & 47.01 & 8.32 & 0.01 & 0.24 & 0.60 & 0.15 \\
\hline Paraoxonase, $\mathrm{U} / \mathrm{mL}$ & 102.56 & 96.69 & 100.46 & 100.49 & 100.21 & 5.77 & 0.02 & 0.04 & 0.39 & 0.11 \\
\hline Total bilirubin,${ }^{5} \mu \mathrm{mol} / \mathrm{L}$ & 2.44 & 3.09 & 2.75 & 2.91 & 2.92 & 0.14 & $<0.001$ & 0.01 & 0.46 & 0.06 \\
\hline \multicolumn{11}{|l|}{ Inflammation } \\
\hline Albumin, g/L & 36.45 & 36.31 & 36.63 & 36.40 & 36.44 & 0.46 & 0.69 & 0.51 & 0.92 & 0.64 \\
\hline Ceruloplasmin, $\mu \mathrm{mol} / \mathrm{L}$ & 3.43 & 3.39 & 3.37 & 3.40 & 3.39 & 0.14 & 0.73 & 0.99 & 0.91 & 0.99 \\
\hline $\mathrm{FRAP}^{5} \mu \mathrm{mol} / \mathrm{L}$ & 135.83 & 126.41 & 124.37 & 124.97 & 123.90 & 3.64 & 0.01 & 0.46 & 0.51 & 0.80 \\
\hline $\mathrm{NO}_{2}^{-}, \mu \mathrm{mol} / \mathrm{L}$ & 4.30 & 4.47 & 4.43 & 4.26 & 4.11 & 0.17 & 0.41 & 0.24 & 0.06 & 0.98 \\
\hline $\mathrm{NO}_{3}^{-}, \mu \mathrm{mol} / \mathrm{L}$ & 14.47 & 15.03 & 14.39 & 14.55 & 14.78 & 0.29 & 0.06 & 0.06 & 0.74 & 0.04 \\
\hline $\mathrm{NOx},{ }^{5} \mu \mathrm{mol} / \mathrm{L}$ & 18.58 & 19.28 & 19.15 & 18.65 & 18.89 & 0.31 & 0.04 & 0.17 & 0.19 & 0.22 \\
\hline Retinol, ${ }^{4} \mu \mathrm{g} / 100 \mathrm{~mL}$ & 38.55 & 35.28 & 37.78 & 35.26 & 38.31 & 2.10 & 0.03 & 0.13 & 0.11 & 0.69 \\
\hline ROMt, mg of $\mathrm{H}_{2} \mathrm{O}_{2} / 100 \mathrm{~mL}$ & 15.84 & 15.78 & 15.41 & 15.85 & 15.49 & 0.58 & 0.92 & 0.72 & 0.80 & 0.93 \\
\hline
\end{tabular}

${ }^{1} \mathrm{~A} 0=$ ad libitum intake, abomasal infusion of water; R0 = restricted intake, abomasal infusion of water; R6.25 = restricted intake, abomasal infusion of $6.25 \mathrm{~g} / \mathrm{d}$ of choline; R12.5 = restricted intake, abomasal infusion of $12.5 \mathrm{~g} / \mathrm{d}$ of choline; R25 = restricted intake, abomasal infusion of 25 $\mathrm{g} / \mathrm{d}$ of choline. Choline was provided via $70 \%$ aqueous solution of choline chloride (Balchem Corporation, New Hampton, NY) mixed with water. ${ }^{2} \mathrm{AST}=$ aspartate aminotransferase; GGT $=\gamma$-glutamyl transpeptidase; $\mathrm{FRAP}=$ ferric reducing ability of plasma; $\mathrm{NO}_{2}{ }^{-}=$nitrite $; \mathrm{NO}_{3}{ }^{-}=$ nitrate; $\mathrm{NOx}=$ nitric oxide metabolites; $\mathrm{ROMt}=$ reactive oxygen species, total

${ }^{3}$ Contrasts: 1 = A0 compared with R0; $2=\mathrm{R} 0$ compared with the average of the 3 treatments $(6.25,12.5$, and $25 \mathrm{~g} / \mathrm{d}$ of choline). Linear (L) and quadratic (Q) effects of treatments R0, R6.25, R12.5, and R25.

${ }^{4}$ Treatment $\times$ day, $P \leq 0.05$.

${ }^{5}$ Treatment $\times$ day, $P \leq 0.10$. 
with choline supply could also indicate an increase in energy production, for example, as a result of greater $\beta$-oxidation (Rogers et al., 2014). The fact that R12.5 had the greatest concentration of NADH further supports the hypothesis that those cows experienced the greatest transport of fatty acids into the mitochondria for oxidation.

\section{Met and Choline Metabolism}

The linear increase in hepatic choline with increasing dose indicates that our abomasal infusions successfully delivered choline postruminally. During its metabolism to betaine, choline is first converted to betaine aldehyde via CHDH. Subsequently, betaine aldehyde is converted to betaine via BADH (Slow and Garrow, 2006). Although mRNA abundance of $C H D H$ was lower with choline compared with $\mathrm{R} 0$ and $B A D H$ did not differ with infusion, the increase in hepatic betaine concentration with choline indicated that oxidation of choline to betaine was increased. This increase was likely used to support the remethylation to Met, followed by production of SAM to maintain synthesis of carnitine during an NNB. The changes in $C H D H$ abundance in the present study contrast with previous work on periparturient cows in which long-term ( -28 through $30 \mathrm{~d}$ around calving) RPC supplementation led to greater hepatic $B A D H$ and $C H D H$ expression (Zhou et al., 2017). The abundance of these genes was also increased in vitro when isolated bovine hepatocytes were supplied with choline (Zhou et al., 2018). Thus, we speculate that the increased supply of choline during a feed restriction-induced NNB had an inhibitory effect on $\mathrm{CHDH}$ abundance. Additionally, betaine aldehyde has been observed to be a competitive inhibitor of $\mathrm{CHDH}$ activity (Haubrich and Gerber, 1981; Perrino and Pierce, 2000). While betaine aldehyde was not detected in the present study, suggesting rapid metabolism, changes in CHDH may have been mediated by increased betaine aldehyde synthesis with increased choline supply.

\section{Transsulfuration Pathway}

Cystathionine $\beta$-synthase converts homocysteine to cystathionine using Ser. We have previously reported that homocysteine production may be enhanced by choline supply, and that Met production via MTR and BHMT was enhanced with $\mathrm{R}$ and increasing choline supply (Coleman et al., 2019). Therefore, the decrease in CBS activity with $\mathrm{R}$ and choline supply corresponds with changes in MTR and BHMT activity; more homocysteine was being used to synthesize Met rather than cystathionine for the transsulfuration pathways during $\mathrm{R}$ and with choline supply during a feed restriction-induced NNB. This interpretation is also supported by the decrease in hepatic cystathionine concentration with $\mathrm{R}$ compared with $\mathrm{A} 0$. This result suggests a decreased flux in the transsulfuration pathway with $\mathrm{R}$ and choline, underscoring the importance of maintaining Met production when Met intake (or its supply from microbial protein) is limited during a feed restriction-induced NNB.

The regulation of expression and activity of CBS occurs at multiple levels via hormones and growth factors (Zhu et al., 2018), but of interest here is the regulation by SAM, which can allosterically activate CBS (Banerjee et al., 2003). S-Adenosylmethionine is synthesized from Met via methionine adenosyltransferase (Corrales et al., 2002). Thus, we hypothesized that enhanced Met production with increased choline supply would enhance SAM production, leading to greater CBS activity. However, the decrease in CBS activity indicates that SAM was not being used to activate CBS. Instead, the increase in carnitine concentration in the present study suggests that SAM was being used as a methyl donor in the synthesis of carnitine to support fatty acid oxidation (Grum et al., 1996).

The next step in the transsulfuration pathway is the synthesis of cysteine from cystathionine, which can then be used to produce taurine and GSH. Both taurine and GSH are potent antioxidants that help alleviate ROM damage in the liver (Zhou et al., 2016b). Glutathione is synthesized via 2 enzymes, GCL and GSS (Lushchak, 2012). Glutamate cysteine ligase converts the cysteine to $\gamma$-glutamylcysteine and is the rate-limiting step of GSH synthesis (Chen et al., 2013). This enzyme is a heterodimer made up of a catalytic subunit (GCLC) and a modifier subunit, with GCLC controlling the catalytic activity of the enzyme (Chen et al., 2013). In the second step of GSH synthesis, $\gamma$-glutamylcysteine is used to synthesize reduced GSH (Chen et al., 2013). The reduced GSH that is produced can then be oxidized via the enzyme GSR, and the oxidized GSH can be reduced via GPX1 (Lushchak, 2012). The lack of difference in GSH concentration in liver tissue along with lower mRNA abundance of GCLC and GPX1 with choline suggests that GSH metabolism was not altered significantly by choline supply. Additionally, these results suggest that production of GSH may not be highly regulated at the transcriptional level.

Taurine is also synthesized in the transsulfuration pathway. Cysteinesulfininic acid is synthesized from cysteine by CDO1 and can then be used by CSAD to produce taurine (Park et al., 2017). While CDO1 and $C S A D$ were decreased with $\mathrm{R}$, the decrease in hypotaurine concentration with $\mathrm{R}$ suggests rapid conversion 
to taurine. Despite the lack of change in mRNA abundance of CDO1 and CSAD with choline supply, the greater hepatic taurine concentration suggests increased synthesis with choline supply. In rat liver, changes in CDO activity with variation in sulfur amino acid intake have occurred at the protein rather than mRNA level (Bella et al., 1999a, b). This may partly explain why the difference in taurine concentrations were not related to mRNA expression of CDO1 and CSAD. A change in efficiency of the reaction due to differences in the supply of trace minerals also cannot be discounted, especially taking into account that some $(\mathrm{Fe}, \mathrm{Zn})$ can enhance catalytic activity (at least in the mouse; McCoy et al., 2006). The fact that concentrations of taurocholic acid and tauro-chenodeoxycholic acid were not increased by the greater taurine production (discussed below) suggest that bile acid metabolism might also have contributed to the accumulation of taurine with choline supply.

Together, the changes in GSH and taurine concentrations indicate that when cows were supplemented with choline, the transsulfuration pathway was altered toward production of taurine, rather than GSH. However, it is not clear why cows were synthesizing taurine rather than GSH. A possibility exists that increased taurine was a "tissue-protective" mechanism induced in response to oxidative stress or immune status (SchullerLevis and Park, 2004). In addition, CDO is known to be regulated by cysteine concentration such that high concentrations of cysteine increase CDO activity (Yin et al., 2016). As CBS activity was decreased with choline and $\mathrm{R}$, less cysteine would have been available. Because low cysteine would be expected to reduce taurine synthesis, the change in CBS suggests that something besides cysteine was mediating the production of taurine rather than GSH.

Glutamate cysteine ligase is also regulated by feedback inhibition of GSH (Chen et al., 2013). Although GSH concentrations were not different in the present study, it is possible that they initially increased under low cysteine concentrations, resulting in feedback inhibition of GCL, leading to cysteine being converted to cysteinesulfininic acid, rather than $\gamma$-glutamylcysteine. Finally, the changes in synthesis of taurine and GSH could have been related to bile acid metabolism. In mice, when bile acid recycling was disrupted, changes in hepatic $C D O, C S A D, G C L$, and metabolites indicated that GSH production was decreased, whereas taurine increased (Wang et al., 2018). Although bile acid recycling itself was not measured in the present study, a possibility exists that this process was inhibited by choline during NNB, which resulted in enhanced taurine rather than GSH synthesis. Additionally, secretion of bile is partly stimulated by cholecystokinin, a hormone that is released in response to macronutrient digestion, particularly fat (Dockray, 2012). Thus, it is also possible that DMI restriction per se reduced the amount of bile secreted and subsequently recycled. As such, it could have contributed to enhanced taurine synthesis. The increase in plasma bilirubin with $\mathrm{R}$ and the modest mitigating effect of choline supply suggest that the capacity of the liver to excrete bilirubin into bile was not diminished.

\section{Bile Acid Synthesis Metabolites}

The primary bile acids formed in liver are cholic acid and chenodeoxycholic acid, and they are subsequently conjugated with Gly or taurine for secretion into bile (Chiang, 2013). Ruminants secrete more taurineconjugated bile acids than Gly-conjugated bile acids (Moore and Christie, 1984). Conjugation of bile acids is a 2-step process, catalyzed by cholyl-CoA synthetase and cholyl-CoA-amino acid $N$-acyltransferase (Vessey, 1978). While chenodeoxycholic acid could not be detected in the present study, the tendency for decreased cholic acid concentration suggests that bile acid synthesis was decreased with choline supply. Additionally, the decrease in glyco-chenodeoxycholic acid with choline suggests that conjugation of chenodeoxycholic acid with Gly was also decreased. Surprisingly, the conjugation with Gly also decreased with $\mathrm{R}$ because hepatic Gly was increased with $\mathrm{R}$ and it was not being used in the synthesis of GSH either. If Gly was not being used for these 2 functions, it may have been directed toward its other functions, such as creatine, purine, and heme synthesis (Wang et al., 2013). Despite the greater hepatic concentration of taurine with choline, the lack of change in concentrations of taurocholic acid and tauro-chenodeoxycholic acid indicated that the increased taurine was being used for other processes, such as its antioxidant functions neutralizing hypochlorous acid and enhancing antioxidant enzymes (Marcinkiewicz and Kontny, 2014). It is also worth noting that in guinea pig, rat, and human liver, Gly and taurine were observed to be mutually inhibitory of conjugation reactions (Vessey, 1978). Thus, elevated taurine concentrations may have been exerting an inhibitory effect on conjugation reactions, which may have contributed to the decrease in glyco-chenodeoxycholic acid with increased choline supply.

\section{Biomarkers of Liver Function}

Paraoxonase, a marker of liver function, is synthesized and released from the liver into the bloodstream, where it associates with high-density lipoproteins to protect them from oxidation (Ferré et al., 2002). The 
greater plasma PON concentration with choline supply contrasts with previous work in which RPC was fed during the periparturient period (Zhou et al., 2016a). Additionally, the enzyme AST is primarily found in the liver and is used clinically as an indicator of liver function (Huang et al., 2006). Bilirubin is produced during heme degradation, and increases in circulating bilirubin during the periparturient period reflects impaired clearance by the liver (Assenat et al., 2004). Although plasma AST and bilirubin decreased with choline supply relative to R0, Zahra et al. (2006) observed no difference in plasma AST with RPC supplementation, while Zhou et al. (2016a) found no differences in AST or bilirubin with RPC supplementation. Overall, changes in the plasma concentrations of AST, PON, and bilirubin suggest that liver function was improved with postruminal choline supply during a feed restriction-induced NNB. These improvements in liver function may have been enhanced by the potential increase in fatty acid oxidation described earlier. This is because TAG accumulation is associated with reduced liver function, and increasing fatty acid oxidation would have limited the deposition of TAG.

\section{Biomarkers of Inflammation and Oxidative Stress}

We found few differences in the plasma concentrations of biomarkers of inflammation and oxidative stress with our feed restriction-induced NNB, which is contrary to work with periparturient cows (Bertoni et al., 2008). Increases in FRAP and retinol are positively associated with antioxidant activity (Benzie and Strain, 1996; Trevisi et al., 2011), whereas nitric oxide increases are associated with greater inflammation and oxidative stress (Trevisi et al., 2013). Therefore, the changes in FRAP, retinol, and nitric oxide indicate that our feed restriction model did induce some oxidative stress. The lack of overall choline effects on these biomarkers is consistent with the lack of changes in ROM, FRAP, haptoglobin, ceruloplasmin, and albumin previously observed by Zhou et al. (2016a) when $12.5 \mathrm{~g} / \mathrm{d}$ of choline was supplemented during the periparturient period. Both $\alpha$-tocopherol and $\beta$-carotene can serve as antioxidants (Sordillo and Aitken, 2009). Therefore, the increase in the concentration of both $\alpha$-tocopherol and $\beta$-carotene with R12.5 could indicate greater antioxidant capacity in those cows.

Overall, the lack of changes in the plasma concentrations of biomarkers associated with inflammation and oxidative stress may be attributable to several aspects of our experimental design. One aspect is that first lactation heifers were used in our study. It is well documented that cows in their first lactation are less susceptible to disease incidence than multiparous cows
(Ingvartsen, 2006), suggesting that heifers may inherently have limited the inflammatory response. Another aspect is the length of our NNB. During the 3 wk of the pre- and postpartum period (i.e., the periparturient period), cows experience immense physiological and immunological changes (Trevisi and Minuti, 2018). Therefore, our 4-d feed restriction-induced NNB may not have been long enough to elicit major changes in inflammation and oxidative stress. Additionally, the cows used in the present study were in late lactation and therefore not experiencing the physical stress of calving and the physiological and immunological changes associated with it. This circumstance may also explain the lack of changes in biomarkers of inflammation and oxidative stress.

\section{CONCLUSIONS}

Postruminal choline supply during a feed restriction-induced NNB decreased activity of CBS, while increasing the production of betaine to maintain Met production. As such, Met may provide methyl groups for carnitine synthesis to support fatty acid oxidation. Choline supply altered flux of the transsulfuration pathway toward production of taurine, rather than GSH. Although choline was not associated with improvements in inflammatory status, it could play a role in reducing oxidative stress and improving certain aspects of liver function. Together, these data underscore the importance of regenerating Met during an NNB, especially when choline supply increases. In such circumstances, exogenous choline supply could have a positive effect on liver function.

\section{ACKNOWLEDGMENTS}

The authors acknowledge Ajinomoto Co. Inc. (Tokyo, Japan) for financial support of this research. Abdulrahman S. M. Alharthi is the recipient of a $\mathrm{PhD}$ fellowship from King Saud University (Rihadh, Saudi Arabia).

\section{REFERENCES}

Assenat, E., S. Gerbal-Chaloin, D. Larrey, J. Saric, J.-M. Fabre, P. Maurel, M.-J. Vilarem, and J. M. Pascussi. 2004. Interleukin $1 \beta$ inhibits CAR-induced expression of hepatic genes involved in drug and bilirubin clearance. Hepatology 40:951-960.

Banerjee, R., R. Evande, Ö. Kabil, S. Ojha, and S. Taoka. 2003. Reaction mechanism and regulation of cystathionine $\beta$-synthase. Biochim. Biophys. Acta 1647:30-35.

Batistel, F., J. M. Arroyo, C. I. M. Garces, E. Trevisi, C. Parys, M. A. Ballou, F. C. Cardoso, and J. J. Loor. 2018. Ethyl-cellulose rumen-protected methionine alleviates inflammation and oxidative stress and improves neutrophil function during the periparturient period and early lactation in Holstein dairy cows. J. Dairy Sci. 101:480-490. 
Bella, D. L., C. Hahn, and M. H. Stipanuk. 1999a. Effects of nonsulfur and sulfur amino acids on the regulation of hepatic enzymes of cysteine metabolism. Am. J. Physiol. 277:E144-E153.

Bella, D. L., L. L. Hirschberger, Y. Hosokawa, and M. H. Stipanuk. 1999b. Mechanisms involved in the regulation of key enzymes of cysteine metabolism in rat liver in vivo. Am. J. Physiol. 276:E326E335.

Benzie, I. F., and J. J. Strain. 1996. The ferric reducing ability of plasma (FRAP) as a measure of "antioxidant power": The FRAP assay. Anal. Biochem. 239:70-76.

Bertoni, G., E. Trevisi, X. Han, and M. Bionaz. 2008. Effects of inflammatory conditions on liver activity in puerperium period and consequences for performance in dairy cows. J. Dairy Sci. 91:33003310 .

Bionaz, M., E. Trevisi, L. Calamari, F. Librandi, A. Ferrari, and G. Bertoni. 2007. Plasma paraoxonase, health, inflammatory conditions, and liver function in transition dairy cows. J. Dairy Sci. 90:1740-1750.

Bremer, J. 1983. Carnitine-Metabolism and functions. Physiol. Rev. $63: 1420-1480$

Carter, A. L., T. O. Abney, and D. F. Lapp. 1995. Biosynthesis and metabolism of carnitine. J. Child Neurol. 10(Suppl. 2):2S3-2S7.

Chen, Y., H. Dong, D. C. Thompson, H. G. Shertzer, D. W. Nebert, and V. Vasiliou. 2013. Glutathione defense mechanism in liver injury: Insights from animal models. Food Chem. Toxicol. 60:38-44.

Chiang, J. Y. L. 2013. Bile acid metabolism and signaling. Compr. Physiol. 3:1191-1212.

Coleman, D. N., M. Vailati-Riboni, A. A. Elolimy, F. C. Cardoso, M. Miura, Y.-X. Pan, and J. J. Loor. 2019. Activity of hepatic betaine-homocysteine methyltransferase and methionine synthase and intermediates of the methionine cycle are altered by postruminal supply of choline during negative nutrient balance in Holstein cows. J. Dairy Sci. 102:8305-8318. https://doi.org/10.3168/ jds.2019-16204.

Cooke, R. F., N. Silva Del Rio, D. Z. Caraviello, S. J. Bertics, M. H. Ramos, and R. R. Grummer. 2007. Supplemental choline for prevention and alleviation of fatty liver in dairy cattle. J. Dairy Sci. 90:2413-2418

Corrales, F. J., I. Pérez-Mato, M. M. Sánchez del Pino, F. l. Ruiz, C. Castro, E. R. García-Trevijano, U. Latasa, M. L. MartínezChantar, A. Martínez-Cruz, M. A. Avila, and J. M. Mato. 2002. Regulation of mammalian liver methionine adenosyltransferase. J. Nutr. 132:2377S-2381S.

de Veth, M. J., V. M. Artegoitia, S. R. Campagna, H. Lapierre, F. Harte, and C. L. Girard. 2016. Choline absorption and evaluation of bioavailability markers when supplementing choline to lactating dairy cows. J. Dairy Sci. 99:9732-9744.

Dockray, G. J. 2012. Cholecystokinin. Curr. Opin. Endocrinol. Diabetes Obes. 19:8-12

Du, X., T. Shen, H. Wang, X. Qin, D. Xing, Q. Ye, Z. Shi, Z. Fang, Y. Zhu, Y. Yang, Z. Peng, C. Zhao, B. Lv, X. Li, G. Liu, and X. Li. 2018. Adaptations of hepatic lipid metabolism and mitochondria in dairy cows with mild fatty liver. J. Dairy Sci. 101:9544-9558.

Elek, P., T. Gaal, and F. Husveth. 2013. Influence of rumen-protected choline on liver composition and blood variables indicating energy balance in periparturient dairy cows. Acta Vet. Hung. 61:59-70.

Fast, D. G., and D. E. Vance. 1995. Nascent VLDL phospholipid composition is altered when phosphatidylcholine biosynthesis is inhibited: Evidence for a novel mechanism that regulates VLDL secretion. Biochim. Biophys. Acta 1258:159-168

Ferré, N., J. Camps, E. Prats, E. Vilella, A. Paul, L. Figuera, and J. Joven. 2002. Serum paraoxonase activity: A new additional test for the improved evaluation of chronic liver damage. Clin. Chem. $48: 261-268$.

Grum, D. E., J. K. Drackley, R. S. Younker, D. W. LaCount, and J. J. Veenhuizen. 1996. Nutrition during the dry period and hepatic lipid metabolism of periparturient dairy cows. J. Dairy Sci. 79:1850-1864.

Haubrich, D. R., and N. H. Gerber. 1981. Choline dehydrogenase: Assay, properties and inhibitors. Biochem. Pharmacol. 30:2993-3000.
Huang, X.-J., Y.-K. Choi, H.-S. Im, O. Yarimaga, E. Yoon, and H.-S Kim. 2006. Aspartate aminotransferase (AST/GOT) and alanine aminotransferase (ALT/GPT) detection techniques. Sensors (Basel) 6:756-782.

Ingvartsen, K. L. 2006. Feeding- and management-related diseases in the transition cow: Physiological adaptations around calving and strategies to reduce feeding-related diseases. Anim. Feed Sci. Technol. 126:175-213

Li, X., W. Huang, J. Gu, X. Du, L. Lei, X. Yuan, G. Sun, Z. Wang, X. Li, and G. Liu. 2015. SREBP-1c overactivates ROS-mediated hepatic NF- $\mathrm{BB}$ inflammatory pathway in dairy cows with fatty liver. Cell. Signal. 27:2099-2109.

Li, Z., and D. E. Vance. 2008. Phosphatidylcholine and choline homeostasis. J. Lipid Res. 49:1187-1194.

Loor, J. J., M. Bionaz, and J. K. Drackley. 2013. Systems physiology in dairy cattle: Nutritional genomics and beyond. Annu. Rev. Anim. Biosci. 1:365-392. https://doi.org/10.1146/annurev-animal $-031412-103728$

Lushchak, V. I. 2012. Glutathione homeostasis and functions: Potential targets for medical interventions. J. Amino Acids 2012:736837.

Marcinkiewicz, J., and E. Kontny. 2014. Taurine and inflammatory diseases. Amino Acids 46:7-20.

McCoy, J. G., L. J. Bailey, E. Bitto, C. A. Bingman, D. J. Aceti, B. G. Fox, and G. N. Phillips Jr.. 2006. Structure and mechanism of mouse cysteine dioxygenase. Proc. Natl. Acad. Sci. USA 103:3084-3089.

Mehta, A. K., N. Arora, S. N. Gaur, and B. P. Singh. 2009. Choline supplementation reduces oxidative stress in mouse model of allergic airway disease. Eur. J. Clin. Invest. 39:934-941.

Moore, J. H., and W. W. Christie. 1984. Digestion, absorption and transport of fats in ruminant animals. Pages 123-149 in Fats in Animal Nutrition. J. Wiseman, ed. Butterworths, London, UK.

Moyes, K. M., J. K. Drackley, J. L. Salak-Johnson, D. E. Morin, J. C. Hope, and J. J. Loor. 2009. Dietary-induced negative energy balance has minimal effects on innate immunity during a Streptococcus uberis mastitis challenge in dairy cows during midlactation. J. Dairy Sci. 92:4301-4316.

NRC. 2001. Nutrient Requirements of Dairy Cattle. 7th rev. ed. Natl. Acad. Press, Washington, DC.

Osorio, J. S., P. Ji, J. K. Drackley, D. Luchini, and J. J. Loor. 2014a Smartamine M and MetaSmart supplementation during the peripartal period alter hepatic expression of gene networks in 1-carbon metabolism, inflammation, oxidative stress, and the growth hormone-insulin-like growth factor 1 axis pathways. J. Dairy Sci. 97:7451-7464.

Osorio, J. S., E. Trevisi, P. Ji, J. K. Drackley, D. Luchini, G. Bertoni, and J. J. Loor. 2014b. Biomarkers of inflammation, metabolism, and oxidative stress in blood, liver, and milk reveal a better immunometabolic status in peripartal cows supplemented with Smartamine M or MetaSmart. J. Dairy Sci. 97:7437-7450.

Park, E., S. Y. Park, I. S. Cho, B. S. Kim, and G. Schuller-Levis. 2017. A novel cysteine sulfinic acid decarboxylase knock-out mouse: Taurine distribution in various tissues with and without taurine supplementation. Pages 461-474 in Taurine 10. Advances in Experimental Medicine and Biology. Vol. 975. D. H. Lee, S. W. Schaffer, E. Park, and H. W. Kim, ed. Springer Netherlands, Dordrecht, the Netherlands.

Perrino, L. A., and S. K. Pierce. 2000. Choline dehydrogenase kinetics contribute to glycine betaine regulation differences in Chesapeake Bay and Atlantic oysters. J. Exp. Zool. 286:250-261.

Pinotti, L., A. Baldi, and V. Dell'Orto. 2002. Comparative mammalian choline metabolism with emphasis on the high-yielding dairy cow. Nutr. Res. Rev. 15:315-332.

Rebouche, C. J., and H. Seim. 1998. Carnitine metabolism and its regulation in microorganisms and mammals. Annu. Rev. Nutr. 18:39-61.

Roche, J. R., A. W. Bell, T. R. Overton, and J. J. Loor. 2013. Nutritional management of the transition cow in the 21st century-A paradigm shift in thinking. Anim. Prod. Sci. 53:1000-1023. 
Rogers, G. W., S. Nadanaciva, R. Swiss, A. S. Divakaruni, and Y. Will. 2014. Assessment of fatty acid beta oxidation in cells and isolated mitochondria. Curr. Protoc. Toxicol. 60:25.23.21-25.23.19.

Sachan, D. S., N. Hongu, and M. Johnsen. 2005. Decreasing oxidative stress with choline and carnitine in women. J. Am. Coll. Nutr. 24:172-176.

Schuller-Levis, G. B., and E. Park. 2004. Taurine and its chloramine: Modulators of immunity. Neurochem. Res. 29:117-126.

Slow, S., and T. A. Garrow. 2006. Liver choline dehydrogenase and kidney betaine-homocysteine methyltransferase expression are not affected by methionine or choline intake in growing rats. J. Nutr. 136:2279-2283.

Sordillo, L. M., and S. L. Aitken. 2009. Impact of oxidative stress on the health and immune function of dairy cattle. Vet. Immunol. Immunopathol. 128:104-109.

Strømland, Ø., M. Niere, A. A. Nikiforov, M. R. VanLinden, I. Heiland, and M. Ziegler. 2019. Keeping the balance in NAD metabolism. Biochem. Soc. Trans. 47:119-130.

Sun, F., Y. Cao, C. Cai, S. Li, C. Yu, and J. Yao. 2016. Regulation of nutritional metabolism in transition dairy cows: Energy homeostasis and health in response to post-ruminal choline and methionine. PLoS One 11:e0160659.

Trevisi, E., G. Bertoni, R. Lombardelli, and A. Minuti. 2013. Relation of inflammation and liver function with the plasma cortisol response to adrenocorticotropin in early lactating dairy cows. J. Dairy Sci. 96:5712-5722.

Trevisi, E., P. Grossi, F. P. Cappelli, S. Cogrossi, and G. Bertoni. 2011. Attenuation of inflammatory response phenomena in periparturient dairy cows by the administration of an $\omega 3$ rumen protected supplement containing vitamin E. Ital. J. Anim. Sci. 10:e61.

Trevisi, E., and A. Minuti. 2018. Assessment of the innate immune response in the periparturient cow. Res. Vet. Sci. 116:47-54.

Vailati Riboni, M., S. Meier, N. V. Priest, C. R. Burke, J. K. Kay, S. McDougall, M. D. Mitchell, C. G. Walker, M. Crookenden, A. Heiser, J. R. Roche, and J. J. Loor. 2015. Adipose and liver gene expression profiles in response to treatment with a nonsteroidal antiinflammatory drug after calving in grazing dairy cows. J. Dairy Sci. 98:3079-3085

Vailati-Riboni, M., Z. Zhou, C. B. Jacometo, A. Minuti, E. Trevisi, D. N. Luchini, and J. J. Loor. 2017. Supplementation with rumenprotected methionine or choline during the transition period influences whole-blood immune response in periparturient dairy cows. J. Dairy Sci. 100:3958-3968.

Vance, D. E., C. J. Walkey, and Z. Cui. 1997. Phosphatidylethanolamine N-methyltransferase from liver. Biochim. Biophys. Acta 1348:142-150.

Vessey, D. A. 1978. The biochemical basis for the conjugation of bile acids with either glycine or taurine. Biochem. J. 174:621-626.

Wang, W., Z. Wu, Z. Dai, Y. Yang, J. Wang, and G. Wu. 2013. Glycine metabolism in animals and humans: Implications for nutrition and health. Amino Acids 45:463-477.

Wang, Y., J. Li, D. Matye, Y. Zhang, K. Dennis, W.-X. Ding, and T. Li. 2018. Bile acids regulate cysteine catabolism and glutathione regeneration to modulate hepatic sensitivity to oxidative injury. JCI Insight 3:e99676.

Wu, H., A. D. Southam, A. Hines, and M. R. Viant. 2008. Highthroughput tissue extraction protocol for NMR- and MS-based metabolomics. Anal. Biochem. 372:204-212.

Wu, P., W.-D. Jiang, Y. Liu, G.-F. Chen, J. Jiang, S.-H. Li, L. Feng, and X.-Q. Zhou. 2014. Effect of choline on antioxidant defenses and gene expressions of Nrf2 signaling molecule in the spleen and head kidney of juvenile Jian carp (Cyprinus carpio var. Jian). Fish Shellfish Immunol. 38:374-382.

Yin, J., W. Ren, G. Yang, J. Duan, X. Huang, R. Fang, C. Li, T. Li, Y. Yin, Y. Hou, S. W. Kim, and G. Wu. 2016. L-Cysteine metabolism and its nutritional implications. Mol. Nutr. Food Res. 60:134-146.

Zahra, L. C., T. F. Duffield, K. E. Leslie, T. R. Overton, D. Putnam, and S. J. LeBlanc. 2006. Effects of rumen-protected choline and monensin on milk production and metabolism of periparturient dairy cows. J. Dairy Sci. 89:4808-4818.

Zhou, Y. F., Z. Zhou, F. Batistel, I. Martinez-Cortés, R. T. Pate, D. L. Luchini, and J. J. Loor. 2018. Methionine and choline supply alter transmethylation, transsulfuration, and cytidine 5'-diphosphocholine pathways to different extents in isolated primary liver cells from dairy cows. J. Dairy Sci. 101:11384-11395.

Zhou, Z., O. Bulgari, M. Vailati-Riboni, E. Trevisi, M. A. Ballou, F. C. Cardoso, D. N. Luchini, and J. J. Loor. 2016a. Rumen-protected methionine compared with rumen-protected choline improves immunometabolic status in dairy cows during the peripartal period. J. Dairy Sci. 99:8956-8969.

Zhou, Z., T. A. Garrow, X. Dong, D. N. Luchini, and J. J. Loor. 2017. Hepatic activity and transcription of betaine-homocysteine methyltransferase, methionine synthase, and cystathionine synthase in periparturient dairy cows are altered to different extents by supply of methionine and choline. J. Nutr. 147:11-19.

Zhou, Z., M. Vailati-Riboni, D. N. Luchini, and J. J. Loor. 2016b. Methionine and choline supply during the periparturient period alter plasma amino acid and one-carbon metabolism profiles to various extents: Potential role in hepatic metabolism and antioxidant status. Nutrients 9:pii:E10.

Zhou, Z., M. Vailati-Riboni, E. Trevisi, J. K. Drackley, D. N. Luchini, and J. J. Loor. 2016c. Better postpartal performance in dairy cows supplemented with rumen-protected methionine compared with choline during the peripartal period. J. Dairy Sci. 99:8716-8732.

Zhu, H., S. Blake, K. T. Chan, R. B. Pearson, and J. Kang. 2018. Cystathionine $\beta$-synthase in physiology and cancer. BioMed Res. Int. 2018:3205125.

Zhu, Y., G. Liu, X. Du, Z. Shi, M. Jin, X. Sha, X. Li, Z. Wang, and X. Li. 2019. Expression patterns of hepatic genes involved in lipid metabolism in cows with subclinical or clinical ketosis. J. Dairy Sci. 102:1725-1735

Zom, R. L. G., J. van Baal, R. M. A. Goselink, J. A. Bakker, M. J. de Veth, and A. M. van Vuuren. 2011. Effect of rumen-protected choline on performance, blood metabolites, and hepatic triacylglycerols of periparturient dairy cattle. J. Dairy Sci. 94:4016-4027. 